\title{
Neurological symptoms, evaluation and treatment in Danish patients with achondroplasia and hypochondroplasia
}

\author{
Mia Aagaard Doherty ${ }^{1,2 *}$, Niels Thomas Hertel ${ }^{3}$, Hanne Buciek Hove ${ }^{4}$ and Annette Haagerup 1,2,5* \\ 'NIDO|Danmark, Hospitalsenheden Vest RM, Denmark \\ ${ }^{2}$ Centre for Rare Diseases, Department of Paediatrics, Aarhus University Hospital, Denmark \\ ${ }^{3}$ Department of Paediatrics, H.C. Andersen Children's Hospital, Odense University Hospital, Denmark \\ ${ }^{4}$ Centre for Rare Diseases, Department of Clinical Genetics, Rigshospitalet, Copenhagen University Hospital, Denmark \\ ${ }^{5}$ Institute of Clinical Medicine, Health, Aarhus University, Denmark
}

\section{Article Info}

\section{Article Notes}

Received: April 20, 2017

Accepted: July 05, 2017

\section{${ }^{*}$ Correspondence: \\ Mia Aagaard Doherty}

E-mail: miadoh@rm.dk

Annette Haagerup

E-mail: annehaag@rm.dk

NIDO|Danmark, Hospitalsenheden Vest RM, Denmark GI. Landevej 61, 7400 Herning, Denmark

(c) 2017 Doherty MA \& Haagerup A. This article is distributed under the terms of the Creative Commons Attribution 4.0 International License.

\section{Keywords}

Achondroplasia

Genotype

Hypochondroplasia

MRI scan

Neurological symptoms

Phenotype

\section{ABSTRACT}

Aim: To investigate the prevalence of neurological symptoms and the types of complications in a cohort of Danish patients with mutation verified achondroplasia and hypochondroplasia and compare the results with previously reported findings.

Methods: Retrospective descriptive study by chart review of patients followed in three outpatients clinics in the period 1997-2014. Forty-eight patients with achondroplasia and a median age of 9,5 years old and 20 patients with hypochondroplasia and a median age of 12 years old were enrolled. Neurological manifestations, epidemiological variables and clinical data were collected.

Results: Data on neurological symptoms and surgical interventions were extracted and compared with existing knowledge. Description of phenotypes revealed frequent headaches, pain in back, neck and lower limbs, sleep apnoea and conductive hearing loss. No sub-phenotype was predictive for referral to an MRI scan or neurosurgery.

Conclusion: Through investigation of phenotypes and genotypes in patients with achondroplasia and hypochondroplasia we report the frequencies of neurological symptoms, foramen magnum stenosis, spinal cord compression and neurosurgery in Danish patients. Variation in the evaluation of patients among the three clinics is found and discussed. To further standardise the management of patients, national guidelines for follow-up on children with $\mathrm{ACH}$ and $\mathrm{HCH}$ are recommended.

\section{Keynotes}

- Achondroplasia and hypochondroplasia patients can suffer from a small foramen magnum and a narrow spinal canal. Untreated this may lead to serious impediments.

- Foramen magnum stenosis was present in $54,2 \%$ and hydrocephalus was seen in $18,7 \%$ of the achondroplasia patients. A MRI scan of the cerebrum was performed in $62,5 \%$ of patients in this group.

- To standardise the management of these patients we recommend continuing collaboration and consensus of a national strategy for follow-up.

\section{Introduction}

Achondroplasia (ACH) (OMIM \#100800) is the most common 
form of skeletal dysplasia affecting over 250,000 people worldwide with a birth prevalence of 1 in 20,000-30,000 live-born infants ${ }^{1}$. It is inherited as an autosomal dominant trait with complete penetrance, but $80-90 \%$ of the cases are caused by de novo mutations ${ }^{2}$. Most cases are caused by one of two point mutations, G1138A or G1138C, and both mutations result in an amino acid substitution at position 380 of the fibroblast growth factor receptor 3 (FGFR3) ${ }^{3}$.

Hypochondroplasia (HCH) (OMIM \#146000) and ACH have been proposed to be allelic disorders ${ }^{4}$. The C1620A mutation and the $\mathrm{C} 1620 \mathrm{G}$ mutation in FGFR3 are recurrent in patients with $\mathrm{HCH}^{5}$. A number of patients do not have this mutation suggesting that $\mathrm{HCH}$ may also be caused by other mutations in FGFR3 or perhaps a mutation in another gene $^{6}$. Patients with HCH may have the same clinical and radiological manifestations as $\mathrm{ACH}$ but the phenotype is usually less severe ${ }^{7}$.

Disproportionate growth between endochondral and membranous bone and the organs underneath causes different complications for individuals with ACH and $\mathrm{HCH}$. The characteristic phenotype is abnormal short stature with rhizomelia, narrow trunk and macrocephaly ${ }^{8,9}$. Because of defective endochondral ossification patients can suffer from a small, abnormally shaped foramen magnum. They have short pedicles, small neural foramina, and reduced interpedicular distance caudally and with age they are at risk of developing spinal canal stenosis. This may lead to serious impediments such as myelopathy, apnoea and sudden death ${ }^{10-12}$. ACH patients also suffer from midfacial underdevelopment and that results in short Eustachian tubes and the tonsils and adenoids may be too large for the available space and this may cause respiratory symptoms ${ }^{13}$. The aim of this study is to investigate the prevalence of neurological symptoms and the general complications in a cohort of Danish patients with ACH and HCH as well as to describe the cohort regarding phenotype and genotype and compare the results with previously reported findings.

\section{Patients and methods}

All patients with $\mathrm{ACH}$ and $\mathrm{HCH}$ followed in the three outpatient clinics, Centre for Rare Diseases at Aarhus University Hospital (AUH) and Rigshospitalet (RH) in Copenhagen and H.C. Andersen Children's Hospital, Odense University Hospital (OUH) in the period 19972014 were included. Data was collected by chart reviews. The patients were registered with core date in RAREDIS ${ }^{\circledR}$, the Nordic database for rare and genetic diseases (www. raredis.eu). The study population comprised 68 patients, 48 patients with $\mathrm{ACH}$ and 20 patients with $\mathrm{HCH}$. There was no significant sex difference with $46 \%$ males in the ACH population and $55 \%$ males in the $\mathrm{HCH}$ population.

A positive family history was seen in four of the $48 \mathrm{ACH}$ patients, two of them being siblings, and in seven of the 20
HCH patients, six consisting of three sets of siblings. The ACH patients were born in the period of 1960-2014 while the HCH patients were born in the period 1969-2012. The median age of the ACH patients was 9,5 years ranging from four months to 54 years old and it was 12 years ranging from two to 45 years old in the $\mathrm{HCH}$ patients.

Neurological manifestations considered relevant in this study were among others stenosis of foramen magnum, hypotonia, and hydrocephalus as described in the literature ${ }^{10,11,14}$. Data on epidemiological variables and clinical data such as phenotypic features, respiratory problems and rate of development were collected as well as the genotype. It was noticed if the patients had been examined with a magnetic resonance imaging scan (MRI scan) or other forms of medical examinations or had been through neurosurgery such as decompression in the spinal canal or insertion of a shunt or both. Each patient's chart was read from either birth or from time of referral to one of the three outpatients clinics at $\mathrm{AUH}, \mathrm{RH}$ or $\mathrm{OUH}$ and until autumn of 2014. Data were summarised, organized and analysed for correlations.

Data are reported as median values and range unless otherwise indicated. Pearson's chi-square was used to compare different groups. $\mathrm{p}<0,05$ was considered significant. An approval by an ethical committee was not applicable in this study. The study is registered according to the Danish Data Protection Agency and is not connected with any conflict of interests.

\section{Results}

\section{Neurological manifestations and interventions}

Review of the medical records of the ACH patients revealed 26 patients having foramen magnum stenosis $(54,2 \%)$. Ten of the 26 patients had severe symptoms that had led to a foramen magnum decompression operation $(20,8 \%)$. The median age of their first operation was one year old ranging from four months to 15 years old. In the HCH patient group one had a stenosis and was treated with an operation at the age of 10 months. The frequency of neurological symptoms in patients with $\mathrm{ACH}$ and $\mathrm{HCH}$ in this cohort is shown in table 1 and 2 .

The reporting of clonus and hypo- and hyperreflexia was low. In the group of patients with ACH clonus was reported in four cases $(8,3 \%)$, hyporeflexia in two cases $(4,1 \%)$ and hyperreflexia in three cases $(6,3 \%)$. Clonus was present in different periods of time in the four patients, approximately three years being the longest in a patient from the age of one year old to four years old. The pathological reflexes were reported to have lasted for a short period of time in the five patients. As expected the percentages of all the symptoms in the group that underwent surgery were higher compared to all the ACH patients except for hypotonia. But 
Table 1: Neurological manifestations in patients with achondroplasia.

\begin{tabular}{lcccc}
\hline & \multicolumn{2}{c}{$\begin{array}{c}\text { All patients with } \\
\text { ACH } \mathbf{n A C H}=\mathbf{4 8}\end{array}$} & $\begin{array}{c}\text { Patients with } \mathrm{ACH} \text { in need } \\
\text { of neurosurgery } \mathrm{nACH}=\mathbf{1 6}\end{array}$ \\
\hline \multicolumn{1}{c}{ Sign/symptom } & No. & Percentage & No. & Percentage \\
Epilepsy & 2 & 4,2 & 2 & 12,5 \\
Headache & 14 & 29,2 & 6 & 37,5 \\
Nausea & 6 & 12,5 & 4 & 25,0 \\
Sleep apnoea & 17 & 35,4 & 8 & 50,0 \\
Pain back/neck & 20 & 41,7 & 7 & 43,8 \\
Pain lower limbs & 24 & 50,0 & 9 & 56,3 \\
Hypotonia & 19 & 39,6 & 6 & 37,5 \\
Paraesthesia & 5 & 10,4 & 2 & 12,5 \\
Bladder dysfunction & 2 & 4,2 & 2 & 12,5 \\
Bowel dysfunction & 2 & 4,2 & 2 & 12,5 \\
\hline ACH, ach
\end{tabular}

$\mathrm{ACH}$, achondroplasia

Table 2: Neurological manifestations in 20 patients with hypochondroplasia.

\begin{tabular}{lcc}
\hline \multicolumn{1}{c}{ Sign/symptom } & No. & Percentage \\
\hline Epilepsy & 2 & 10 \\
Headache & 4 & 20 \\
Nausea & 1 & 5 \\
Sleep apnoea & 3 & 15 \\
Pain back/neck & 3 & 15 \\
Pain lower limbs & 7 & 35 \\
Hypotonia & 3 & 15 \\
Paraesthesia & 0 & 0 \\
Bladder dysfunction & 1 & 5 \\
Bowel dysfunction & 0 & 0 \\
\hline
\end{tabular}

Only one patient with hypochondroplasia was in need of surgery (See table 3 and 4 ) there was no significant difference in the frequencies of any of the symptoms between the two groups. The percentages of neurological symptoms were lower in the $\mathrm{HCH}$ group except for bladder dysfunction and epileptic seizures.

Nine ACH patients were reported having hydrocephalus $(18,7 \%)$ and five of them were treated with a shunt $(10,4 \%)$. The median age of the procedure was five years old ranging from 10 months to 15 years old. It is difficult to say which symptoms indicate hydrocephalus as none of the five patients who had a shunt inserted suffered from the exact same symptoms. The most frequent symptoms in the five patients were headache and nausea and the symptoms were seen in combination with pathological neuroimaging to be indicators for surgery (Table 3). Correspondingly two of the $\mathrm{HCH}$ patients had hydrocephalus $(10 \%)$ and one of them $(5 \%)$ needed treatment at the age of six months.

An MRI scan of the cerebrum is the most important investigation to confirm a stenosis in the spinal canal. In the ACH group 30 patients were reported to have had an MRI scan of the cerebrum $(62,5 \%)$. The median age of their first scan was one year ranging from a few months to 50 years. Only four of the patients scanned did not have stenosis at the foramen magnum level $(13,3 \%)$. Of the $26 \mathrm{ACH}$ patients with stenosis in the spinal canal diagnosed through an MRI scan $61,5 \%$ required operation because of neurological symptoms (Table 3 and 4). The decision criteria for surgery varied, however most operations were performed due to a combination of pathological neuroimaging and symptoms such as hypotonia and sleep apnoea. There was no clear

Table 3: Neurological symptoms of patients with $\mathrm{ACH}$ or $\mathrm{HCH}$ who have been operated (Decompression (D), shunt (S) or $\mathrm{D}+\mathrm{S}) \mathrm{n}=17$.

\begin{tabular}{|c|c|c|c|c|c|c|c|c|c|c|}
\hline \multirow[t]{2}{*}{ Pt. } & \multirow[t]{2}{*}{ Diag. } & \multicolumn{9}{|c|}{ Neurological symptoms } \\
\hline & & Headache & Nausea & $\begin{array}{c}\text { Sleep } \\
\text { apnoea }\end{array}$ & $\begin{array}{c}\text { Pain back/ } \\
\text { neck }\end{array}$ & $\begin{array}{l}\text { Pain lower } \\
\text { limbs }\end{array}$ & Hypotonia & Paraesthesia & $\begin{array}{l}\text { Bladder dys- } \\
\text { function }\end{array}$ & $\begin{array}{l}\text { Bowel dys- } \\
\text { function }\end{array}$ \\
\hline 1 & $\mathrm{ACH}(\mathrm{D})$ & & & & & & + & & & \\
\hline 2 & $\mathrm{ACH}(\mathrm{D})$ & & + & + & & & & & & \\
\hline 3 & $\mathrm{ACH}(\mathrm{D})$ & & & + & & & + & & & \\
\hline 4 & $\mathrm{ACH}(\mathrm{D})$ & & & & & & + & & & \\
\hline 5 & $\mathrm{ACH}(\mathrm{D}+\mathrm{S})$ & + & & & & & & & & \\
\hline 6 & $\mathrm{ACH}(\mathrm{S})$ & & & & & & + & & & \\
\hline 7 & $\mathrm{ACH}(\mathrm{S})$ & + & + & & & + & & & & \\
\hline 8 & $\mathrm{ACH}(\mathrm{D})$ & & & & & + & + & & & \\
\hline 9 & $\mathrm{ACH}(\mathrm{D})$ & & & + & + & + & & & & \\
\hline 10 & $\mathrm{ACH}\left(\mathrm{D}^{*}\right)$ & & & & + & + & & + & + & + \\
\hline 11 & $\mathrm{ACH}(\mathrm{D})$ & & & + & + & + & + & & & \\
\hline 12 & $\mathrm{ACH}(\mathrm{D}+\mathrm{S})$ & + & + & + & + & + & & & & \\
\hline 13 & $\mathrm{ACH}\left(\mathrm{D}^{*}+\mathrm{S}\right)$ & + & + & + & + & & & & & \\
\hline 14 & $\mathrm{ACH}\left(\mathrm{D}^{*}\right)$ & + & & + & + & + & & & & \\
\hline 15 & $\mathrm{ACH}\left(\mathrm{D}^{*}\right)$ & + & & & & + & & + & + & + \\
\hline 16 & $\mathrm{ACH}\left(\mathrm{D}^{*}\right)$ & & & + & + & + & & & & \\
\hline \multirow[t]{2}{*}{17} & $\mathrm{HCH}(\mathrm{D}+\mathrm{S})$ & & + & & & & + & & & \\
\hline & $\begin{array}{l}\text { Subset (\%) of the } 17 \\
\text { patients operated }\end{array}$ & 35,3 & 29,4 & 47,0 & 41,2 & 53,0 & 41,2 & 11,8 & 11,8 & 11,8 \\
\hline
\end{tabular}

*Decompression at the lumbar region Pt. ID, Patient ID; Diag., Diagnosis; ACH, achondroplasia; HCH, hypochondroplasia. 
Table 4: Age at 1st MRI and 1st operation and outcome in the patients with $\mathrm{ACH}$ and $\mathrm{HCH}$ who have been operated (Decompression (D), shunt (S) or $D+S) n=17$

\begin{tabular}{|c|c|c|c|c|c|c|c|}
\hline \multirow[t]{2}{*}{ Pt. ID } & \multirow[t]{2}{*}{ Diag. } & \multicolumn{6}{|c|}{ Operation } \\
\hline & & $\begin{array}{l}\text { 1. MRI } \\
\text { (Age) }\end{array}$ & $\begin{array}{c}\text { 1.operation } \\
\text { (Age) }\end{array}$ & $\begin{array}{l}\text { Decompression } \\
\text { (D) }\end{array}$ & $\begin{array}{l}\text { Shunt } \\
\text { (S) }\end{array}$ & $D+S$ & Outcome \\
\hline 1 & $\mathrm{ACH}$ & $5 \mathrm{mo}$ & $6 \mathrm{mo}$. & + & & & Doing well \\
\hline 2 & $\mathrm{ACH}$ & $3 \mathrm{mo}$. & $4 \mathrm{mo}$. & + & & & On-going breathing troubles \\
\hline 3 & $\mathrm{ACH}$ & $1 y$ & $1 y$ & + & & & Palsy in half of the body not reduced \\
\hline 4 & $\mathrm{ACH}$ & $3 \mathrm{mo}$. & $10 \mathrm{mo}$. & + & & & Doing well \\
\hline 5 & $\mathrm{ACH}$ & $6 \mathrm{mo}$ & $10 \mathrm{mo}$. & + & + & + & Doing well \\
\hline 6 & $\mathrm{ACH}$ & $1 \mathrm{y}$ & $<2 y$ & & + & & Doing well \\
\hline 7 & $\mathrm{ACH}$ & $<5 y$ & $<5 y$ & & + & & Doing well \\
\hline 8 & $\mathrm{ACH}$ & 1 y & 1 y & + & & & Doing well \\
\hline 9 & $\mathrm{ACH}$ & $1 y$ & $2 y$ & + & & & Doing well \\
\hline 10 & $\mathrm{ACH}$ & $4 y$ & $12 \mathrm{y}$ & + & & & Reduced pain in legs \\
\hline 11 & $\mathrm{ACH}$ & $11 \mathrm{mo}$. & $11 \mathrm{mo}$. & + & & & Doing well \\
\hline 12 & $\mathrm{ACH}$ & $6 y$ & $7 y$ & + & + & + & Doing well \\
\hline 13 & $\mathrm{ACH}$ & Not known & $15 y$ & + & + & + & Doing well \\
\hline 14 & $\mathrm{ACH}$ & $19 y$ & 21 y & + & & & Doing well \\
\hline 15 & $\mathrm{ACH}$ & Not known & $19 y$ & + & & & Palsy from chest and down not reduced \\
\hline 16 & $\mathrm{ACH}$ & 42 y & $49 y$ & + & & & Doing well \\
\hline 17 & $\mathrm{HCH}$ & $5 \mathrm{mo}$. & $6 \mathrm{mo}$. & + & + & + & Doing well \\
\hline \multicolumn{2}{|c|}{ Subset (\%) of the } & & & 88,2 & 35,3 & 23,5 & \\
\hline 17 pati & nts operated & & & & & & \\
\hline
\end{tabular}

Pt. ID, Patient ID; Diag., Diagnosis; ACH, achondroplasia; HCH, hypochondroplasia, mo., months old; y, years old; patient $10,14,15$ and 16 had a lumbar decompression surgery

chronology in appearance of the different symptoms in the patients with stenosis. Five $\mathrm{HCH}$ patients were scanned and the median age of the first scan was one year old ranging from a few months to 11 years old. Only one of them showed a foramen magnum stenosis and it required an operation. No specific neurological symptoms correlated to having an MRI scan as most of the patients scanned showed symptoms in various degrees. Most cases had sleep apnoea or hypotonia. But there was no significant difference between the frequency of these symptoms in the patients scanned and the patients not scanned.

A computed tomography scan (CT-scan) was performed on 14 patients with ACH $(29,2 \%)$. Scans on two of the 14 patients confirmed stenosis $(14,3 \%)$. Two $\mathrm{HCH}$ patients went through a CT scan because of potential hydrocephalus. Six ACH patients and three HCH patients had an ultrasound because of a possible hydrocephalus.

In the ACH group 20 reported having back or neck pain at some point in their life $(41,7 \%)$. The disclosure was made from when they were three to 49 years old. Likewise three $\mathrm{HCH}$ patients reported having pain in the back or neck (15\%). In the group of ACH patients 24 reported to have pain in the lower extremities (50\%) while seven $\mathrm{HCH}$ patients said the same (35\%). The symptoms were reported from patients at age three to 48 years old. Most of these patients had both back and leg pain. Interestingly to squat down relieved the back or leg pain in four of the ACH patients. Twenty-one of the $30 \mathrm{ACH}$ patients and one of the eight $\mathrm{HCH}$ patients with pain in the back or neck or lower limbs had an MRI scan to clarify if there was a stenosis in the spinal canal corresponding with $70 \%$ and $12,5 \%$. Seven of the $30 \mathrm{ACH}$ patients with pain had a stenosis in the lower back $(23,3 \%)$. Five ACH patients had a laminectomy $(10,4 \%)$. The median age of the laminectomy in our study was 19 years old ranging from 12 to 51 years old. None of the $\mathrm{HCH}$ patients had a spinal stenosis. Five ACH patients reported symptoms of paraesthesia $(10,4 \%)$ and three were clarified through an MRI scan of whom two went through a decompression procedure. Two ACH patients have permanent neurological injuries such as palsy and incontinence $(4,2 \%)$. One of the two patients debuted with the symptoms at the age of 34 years old and the other has suffered from urinary- and faecal incontinence in all 15 years of his life.

\section{Genotypes}

Of the 48 ACH patients, 68,8\% had the G1138A mutation in the FGFR3 gene. The rest had either not been tested or the data was not available. Of the $20 \mathrm{HCH}$ patients, $80 \%$ had been diagnosed through genetic testing. Among this population there were 7 different mutations leading to $\mathrm{HCH}$ (Table 5). The high prevalence of de novo mutations previously described was confirmed ${ }^{2}$. 
Table 5: Mutations in 20 patients with hypochondroplasia.

\begin{tabular}{lcc}
\hline \multicolumn{1}{c}{ Mutation } & No. & Percentage \\
\hline c. $1620 \mathrm{C}>\mathrm{A}$ & 6 & 30 \\
c. $1052 \mathrm{C}>\mathrm{G}$ & 4 & 20 \\
c. $1612 \mathrm{C}>\mathrm{A}$ & 2 & 10 \\
c. $1948 \mathrm{~A}>\mathrm{C}$ & 1 & 5 \\
c. $970 \mathrm{C}>\mathrm{G}$ & 1 & 5 \\
c. $1619 \mathrm{~A}>\mathrm{G}$ & 1 & 5 \\
c. $2005 \mathrm{C}>\mathrm{G}$ & 1 & 5 \\
Not known & 4 & 20 \\
\hline
\end{tabular}

\section{Respiratory symptoms}

Multiple otitis media is a well-recognised complication of $\mathrm{ACH}^{15,16}$. In this study 27 of the $\mathrm{ACH}$ patients $(56,3 \%)$ and 15 of the $\mathrm{HCH}$ patients (40\%) reported it. Conductive hearing loss among these children is not uncommon and it was seen in 15 of the ACH patients (31,3\%) and in three of the $\mathrm{HCH}$ patients (15\%). Nine ACH patients $(18,8 \%)$ went through a tonsillectomy or insertion of a ventilation tube. The percentage was $5 \%$ in the $\mathrm{HCH}$ group. Snoring was reported in $52 \%$ of the ACH patients. A sleep position in opisthotonus was stated in $25 \%$ of ACH patients' records and in $10 \%$ in the $\mathrm{HCH}$ patients. Sleep apnoea, which both can be caused by compression of the spinal canal and too large tonsils in an undersized throat, was reported in $35,4 \%$ of the $\mathrm{ACH}$ patients and in $15 \%$ of the $\mathrm{HCH}$ patients. Of the $48 \mathrm{ACH}$ patients 21 were evaluated at a respiratory centre $(43,8 \%)$ and 16 ended up getting respiratory therapy for sleep apnoea $(33,3 \%)$. The median age of the test was six years old with a range of 3 months to 40 years old.

\section{Phenotypic characteristics}

Most ACH patients in our population had the phenotypic characteristics such as frontal bossing, bowed legs in particular regarding the tibia bone and rhizomelia. Clinical comparison showed that the patients with $\mathrm{HCH}$ in general had a milder phenotype, as they did not have as many of the characteristics as the ACH patients. The most dominating trait in their group was shortness of the limbs and lumbar lordosis. $62,5 \%$ of the patients with ACH was mentioned having a lordosis and the percentage was $45 \%$ for $\mathrm{HCH}$ patients. Almost every patient in the ACH group was hypermobile whereas it was less recurrent in the $\mathrm{HCH}$ group. The prevalence of elbow and hip extension defect was seen in $31,2 \%$ of the ACH group and it was primarily seen from the age of four years and became more frequent with increasing age. Extention defects was less recurrent in the HCH group.

\section{Discussion}

Medical and surgical interventions were within the range of intervention rates reported for previous cohorts. As mentioned $26 \mathrm{ACH}$ patients had a foramen magnum stenosis $(54,2 \%)$ and 10 had a foramen magnum decompression operation $(20,8 \%)$. The frequency of the operation in other studies was in the range from $6,8 \%-28 \%{ }^{15,17-19}$. The median age at first operation in our population was slightly lower than seen in previous studies. In one study the mean age was 23 months and in another it was 70 months $^{12,17}$. Fifteen of the $26 \mathrm{ACH}$ patients in our study with foramen magnum stenosis were diagnosed before their first year of age $(57,7 \%)$ and the median age of diagnosis for foramen magnum stenosis in our population was one year ranging from three months to 42 years. The percentage of a shunt insertion was slightly higher in our study compared to the newest reports but our result was almost identical with results from a study in $1998(10,4 \% \text { vs. } 10,5 \%)^{15,17,18}$. This may be because the two oldest patients with a shunt in our population were born in the early 1990's with less accurate modes of distinguishing between the benign ventriculomegaly and the pathological hydrocephalus in consideration of the former being very common in $\mathrm{ACH}^{20}$.

In all, $75 \%$ of the $16 \mathrm{ACH}$ patients who underwent operation were confirmed having the most common mutation in $\mathrm{FGFR}^{3}$. The high frequency of this mutation has also been shown in Sweden ${ }^{21}$.

The rest had either not been tested or the data was not available. All who went through a foramen magnum decompression had this mutation, one of the two who had a shunt inserted were confirmed, three of the four who had a foramen magnum decompression and a shunt inserted were confirmed and two of the four, who went through a lumbar laminectomy, were confirmed with the mutation. The one $\mathrm{HCH}$ patient who went through foramen magnum decompression and a shunt insertion had the most common HCH mutation in the FGFR3 gene ${ }^{5}$. These observations show that the genotype cannot predict the later need for neurosurgery.

Anticipatory care should be directed at children who are at high risk of severe complications to be able to intervene in time of emergent problems. A multidisciplinary team of doctors is needed to ensure the best care. Health Supervision Guidelines for Children with ACH have been developed to aid primary care physicians in the management of these children ${ }^{22}$.

Slightly above $60 \%$ had an MRI scan in our population. Thus the Danish clinical tradition in total do not follow the American guidelines with respect to use of neuroimaging since they suggest MRI scans in every infant with $\mathrm{ACH}^{22}$. In an Australasian study 22 of 53 children (41,5\%) were reported as having had MRI or CT studies by age three ${ }^{18}$.

Even though the rate of using neuroimaging was lower in our study the rate of surgical interventions was within or above rates in other studies. Overall we found that patients with severe complications were diagnosed and 
treated according to international standard. There was a slight dissimilarity in the management among the three clinics in this study. In one clinic almost every ACH patient had their first MRI scan in their first year of life and the scans were often repeated several times in their childhood. This suggests a wish to follow the American guidelines ${ }^{22}$. Systematic scanning of the patients was not seen in the other two centres as the MRI scans were mostly indicated by clinical manifestations. The variation of practice in our study may be due to the fact that there is some controversy about when children with ACH should be fully evaluated including an MRI scan to identify possible stenosis in the spinal canal. Multiple authors recommend full investigation in the first six months of life or when first referred and neuroimaging should be repeated at a predetermined interval afterwards ${ }^{17,19,22-24}$. Another author argues against these criteria as it was found that the MRI scans showed that most of the affected children have some degree of cord compression and most of them gain normal motor development and neurological function suddenly within the first two to three years of age as the cord compression disappears ${ }^{25}$. In a recent study 11 multidisciplinary international experts on skeletal dysplasia discussed various statements regarding neurological symptoms in children with $\mathrm{ACH}$ and concludes that they do not recommend universal screening of infants with $\mathrm{ACH}$ due to risks of over treatment and sedation ${ }^{26}$.

Full anaesthesia is required during the MRI scans when the patients are at a young age and the anaesthetic management of these patients is a significant challenge mainly because of associated airway difficulties with the diagnosis. This fact argues against multiple MRI scans without substantial suspicion. Most of the patients in our study who went through an MRI scan had a foramen magnum stenosis and slightly more than half of them needed an operation because of severe symptoms. It suggests that the clinical manifestations are just as important as are the MRI scan results to determine if a procedure is relevant and it would be reasonable to wait with the neuroimaging until symptoms are present. None of the patients experienced sudden death, which is a risk from cord compression. But two patients had permanent neurological sequelae and this, along with a statistical increased risk of sudden death, may advocate for frequent scans even when no symptoms are present.

Epilepsy was reported in two of the patients with $\mathrm{HCH}$. Both of the patients had the $1620 \mathrm{C}>\mathrm{A}$ mutation resulting in Asn540Lys. This correlates to previous studies showing the association between patients with this mutation and temporal lope dysgenesis and epilepsy ${ }^{27,28}$. The association was also just presented in a recent study ${ }^{29}$. No data on possible temporal lope dysgenesis is present in our study and the rate of development of both the $\mathrm{ACH}$ and $\mathrm{HCH}$ patients was described insufficiently in the charts to present any data from. Mental deficiency has previously been reported in $\mathrm{HCH}$ patients as well as learning disorder and mild intellectual delay ${ }^{30,31}$.

The neurological symptoms registered in $\mathrm{ACH}$ patients in this study correspond to the symptoms recently described $^{10}$. The percentage of sleep apnoea in our study was high but within the range seen in other studies ${ }^{15,24,32,33}$. The high rate of sleep apnoea could be due to frequent upper airway infections combined with the midfacial hypoplasia in patients with $\mathrm{ACH}$ and $\mathrm{HCH}$. To reduce the symptom it may be helpful to lower the threshold for tonsillectomies. The number of tonsillectomies or insertion of a ventilation tube in our study was low compared to other studies ${ }^{15,18}$. Snoring was less frequent in our study compared to another ${ }^{32}$. The rate of pain in the lower limbs were similar to another study's cumulative rate $(50 \%$ vs. $47,2 \%)^{15}$. The number of patients with pain in back or neck resemble results in another study although their cumulative rate exceeds ours for patients above age 30 years but the prevalence of bladder dysfunction in our studies is very similar even though our data is limited and therefore not conclusive $(4,2 \% \text { vs. } 3,1 \%)^{15}$. The occurrence of hypotonia was lower in our study compared to another $(39,6 \%$ vs. $58,9 \%)$ and the rate of paraesthesia was higher in our study $(10,4 \% \text { vs. } 2,6 \%)^{24}$. The rate of conductive hearing loss in our study was comparable with other results $(31,3 \%$ vs. $38 \%)$ but the rate of tonsillectomy was low in our study $(18,8 \% \text { vs. } 40 \%)^{15}$. This may be due to underreporting. Of the $48 \mathrm{ACH}$ patients 21 were evaluated at a respiratory centre $(43,8 \%)$ and 16 ended up getting respiratory therapy for sleep apnoea $(33,3 \%)$. The median age of the test was six years old with a range of 3 months to 40 years old. One study reported $64 \%$ of 53 children ranging from zero to five years old to have had formal polysomnography studies by age three ${ }^{18}$.

Our study was conducted as a retrospective study with the limitations of a relatively small cohort and the risk of lack of registration. Strength in our study is that it is experts handling the treatment and control of the patients because the treatment is centralised in Denmark. Another strength is that there is free access for the patients to a public financed health care in Denmark.

A recent published study has shown that using diffusion tensor imaging it may be possible to quantify changes in the brainstem white matter that correlate with the severity of craniocervical junction narrowing in patients with $\mathrm{ACH}^{34}$. This might be a new improved method to identify suitable patients for therapeutic decompression and monitor response to the treatment. In the future medical treatment may be able to both benefit growth and minimise neurological symptoms in patients with $\mathrm{ACH}$ and $\mathrm{HCH}^{35}$. 


\section{Acknowledgements}

We have not received any financial support including grants.

\section{Conclusion}

This study provides an original overview of the clinical manifestations and management of a cohort of Danish patients with $\mathrm{ACH}$ and $\mathrm{HCH}$ and reports new data on the frequency of apnoea, hypotonia and neurosurgery in patients with foramen magnum stenosis. Furthermore we find and discuss variation in the evaluation of the $\mathrm{ACH}$ and $\mathrm{HCH}$ patients between the three clinics included in our study. To standardise the management of these patients we recommend continuing collaboration, national guidelines and a future national or international multicentre prospective study. In such use of the Raredis database would be possible. Thus it will be possible to gain more information about the phenotypic characteristics, neurological symptoms and need for neuroimaging and neurosurgical treatment in $\mathrm{ACH}$ and $\mathrm{HCH}$ patients. The authors' contribution to standardisation of care and management for patients with $\mathrm{ACH}$ regards regular clinical controls and MRI scans of the patients. The authors recommend to enrol patients to clinical controls at skeletal dysplasia clinics with expertise in paediatric neurology twice a year from birth until the age of five and thereafter once a year until the age of 15 years and once at age 30 years. Extra clinical control should take place if indicated by symptoms. Furthermore MRI scans of the brain including the foramen magnum level should be performed at the age of one, three, seven, 15 and 30 years with the latter including MRI scan of columna totalis. With any sign of neurological symptoms additional controls and scans should be performed. The author's recommendation regarding diagnostics and clinical control of $\mathrm{HCH}$ patients also is examination of the patients at skeletal dysplasia clinics with expertise in paediatric neurology. Due to a less severe phenotype the interval of clinical controls and MRI scans should be determined individually.

\section{Abbreviations}

$\mathrm{ACH}$, achondroplasia; $\mathrm{HCH}$, hypochondroplasia; FGFR3, fibroblast growth factor receptor 3; MRI scan, Magnetic Resonance Imaging Scan; CT-scan, Computed Tomography Scan; AUH, Aarhus University Hospital; OUH, Odense University Hospital; RH, Rigshospitalet.

\section{Authors' contributions}

Mia Aagaard Doherty MS had primary responsibility for protocol development, collecting of data and preliminary data analysis and writing the manuscript.

Drs Hanne Hove and Thomas Hertel contributed with additional patients, analysing data and to the writing of the manuscript.
Dr Annette Haagerup initiated the project and supervised the design and execution of the study, performed the final data analyses and supervised and contributed to the writing of the manuscript.

\section{References}

1. Orioli IM, Castilla EE, Barbosa Neto JG. The birth prevalence rates for the skeletal dysplasias. Journal of medical genetics. 1986; 23(4): 32832 .

2. Horton WA, Hall JG, Hecht JT. Achondroplasia. Lancet. 2007; 370(9582): 162-72.

3. Shiang R, Thompson LM, ZhuYZ, et al. Mutations in the transmembrane domain of FGFR3 cause the most common genetic form of dwarfism, achondroplasia. Cell. 1994; 78(2): 335-42.

4. McKusick VA, Kelly TE, Dorst JP. Observations suggesting allelism of the achondroplasia and hypochondroplasia genes. Journal of medical genetics. 1973; 10(1): 11-6.

5. Bellus GA, McIntosh I, Smith EA, et al. A recurrent mutation in the tyrosine kinase domain of fibroblast growth factor receptor 3 causes hypochondroplasia. Nature genetics. 1995; 10(3): 357-9.

6. Ramaswami U, Rumsby G, Hindmarsh PC, et al. Genotype and phenotype in hypochondroplasia. The Journal of pediatrics. 1998; 133(1): 99-102.

7. Song SH, Balce GC, Agashe MV, et al. New proposed clinico-radiologic and molecular criteria in hypochondroplasia: FGFR 3 gene mutations are not the only cause of hypochondroplasia. American journal of medical genetics Part A. 2012; 158a(10): 2456-62.

8. Langer LO, Jr., Baumann PA, Gorlin RJ. Achondroplasia: clinical radiologic features with comment on genetic implications. Clinical pediatrics. $1968 ; 7(8)$ : 474-85.

9. Di Rocco F, Biosse Duplan M, Heuze Y, et al. FGFR3 mutation causes abnormal membranous ossification in achondroplasia. Human molecular genetics. 2014; 23(11): 2914-25.

10. Hecht JT, Bodensteiner JB, Butler IJ. Neurologic manifestations of achondoplasia. Handbook of clinical neurology. 2014; 119: 551-63.

11. Pauli RM, Scott CI, Wassman ER, et al. Apnea and sudden unexpected death in infants with achondroplasia. The Journal of pediatrics. 1984; 104(3): 342-8.

12. Bagley CA, Pindrik JA, Bookland MJ, et al. Cervicomedullary decompression for foramen magnum stenosis in achondroplasia. Journal of neurosurgery. 2006; 104(3 Suppl): 166-72.

13. Cohen MM, Jr., Walker GF, Phillips C. A morphometric analysis of the craniofacial configuration in achondroplasia. Journal of craniofacial genetics and developmental biology Supplement. 1985; 1: 139-65.

14. Mueller SM, Bell W, Cornell S, et al. Achondroplasia and hydrocephalus. A computerized tomographic, roentgenographic, and psychometric study. Neurology. 1977; 27(5): 430-4.

15. Hunter AG, Bankier A, Rogers JG, et al. Medical complications of achondroplasia: a multicentre patient review. Journal of medical genetics. 1998; 35(9): 705-12.

16. Gordon N. The neurological complications of achondroplasia. Brain \& development. 2000;22(1):3-7.

17. King JA, Vachhrajani S, Drake JM, et al. Neurosurgical implications of achondroplasia. Journal of neurosurgery Pediatrics. 2009; 4(4): 297 306.

18. Ireland PJ, Johnson S, Donaghey S, et al. Medical management of children with achondroplasia: evaluation of an Australasian cohort aged 0-5 years. Journal of paediatrics and child health. 2012; 48(5): 443-9. 
19. Pauli RM, Horton VK, Glinski LP, et al. Prospective assessment of risks for cervicomedullary-junction compression in infants with achondroplasia. American journal of human genetics. 1995; 56(3): 732-44.

20. Steinbok P, Hall J, Flodmark O. Hydrocephalus in achondroplasia the possible role of intracranial venous hypertension. Journal of neurosurgery. 1989; 71(1): 42-8.

21. Alderborn A, Anvret M, Gustavson KH, et al. Achondroplasia in Sweden caused by the G1138A mutation in FGFR3. Acta paediatrica (Oslo, Norway : 1992). 1996; 85(12): 1506-7.

22. Trotter TL, Hall JG. Health supervision for children with achondroplasia. Pediatrics. 2005; 116(3): 771-83.

23. Richette $\mathrm{P}$, Bardin T, Stheneur C. Achondroplasia from genotype to phenotype. Joint, bone, spine : revue du rhumatisme. 2008; 75(2): 125-30.

24. Ruiz Garcia M, Tovar Baudin A, Del Castillo Ruiz V, et al. Early detection of neurological manifestations in achondroplasia. Child's nervous system : ChNS : official journal of the International Society for Pediatric Neurosurgery. 1997; 13(4): 208-13.

25. Rimoin DL. Cervicomedullary junction compression in infants with achondroplasia when to perform neurosurgical decompression. American journal of human genetics. 1995; 56(4): 824-7.

26. White KK, Bompadre V, Goldberg MJ, et al. Best practices in the evaluation and treatment of foramen magnum stenosis in achondroplasia during infancy. American journal of medical genetics Part A. 2016; 170(1): 42-51.

27. Kannu P, Hayes IM, Mandelstam S, et al. Medial temporal lobe dysgenesis in hypochondroplasia. American journal of medical genetics Part A. 2005; 138(4): 389-91.

28. Grosso S, Farnetani MA, Berardi R, et al. Medial temporal lobe dysgenesis in Muenke syndrome and hypochondroplasia. American journal of medical genetics Part A. 2003; 120a(1): 88-91.

29. Okazaki T, Saito Y, Ueda R, et al. Epileptic phenotype of FGFR3-related bilateral medial temporal lobe dysgenesis. Brain \& development. 2017; 39(1): 67-71.

30. Hall BD, Spranger J. Hypochondroplasia: clinical and radiological aspects in 39 cases. Radiology. 1979; 133(1): 95-100.

31. Linnankivi $T$, Makitie 0 , Valanne $L$, et al. Neuroimaging and neurological findings in patients with hypochondroplasia and FGFR3 N540K mutation. American journal of medical genetics Part A. 2012; 158a(12): 3119-25.

32. Julliand S, Boule M, Baujat G, et al. Lung function, diagnosis, and treatment of sleep-disordered breathing in children with achondroplasia. American journal of medical genetics Part A. 2012; 158a(8): 1987-93.

33. Mogayzel PJ, Jr., Carroll JL, Loughlin GM, et al. Sleep-disordered breathing in children with achondroplasia. The Journal of pediatrics. 1998; 132(4): 667-71.

34. Bosemani T, Orman G, Carson KA, et al. Diffusion tensor imaging of the brainstem in children with achondroplasia. Developmental medicine and child neurology. 2014; 56(11): 1085-92.

35. Yamashita A, Morioka M, Kishi H, et al. Statin treatment rescues FGFR3 skeletal dysplasia phenotypes. Nature. 2014; 513(7519): 507-11. 